\title{
Le Centre d'Études Médiévales de Prague / Centrum medievistických studií (CMS)
}

\section{Éloïse Adde}

\section{(2) OpenEdition}

\section{Journals}

Édition électronique

URL : http://journals.openedition.org/ifha/235

DOI : $10.4000 /$ ifha.235

ISSN : 2198-8943

\section{Éditeur}

IFRA - Institut franco-allemand (sciences historiques et sociales)

\section{Édition imprimée}

Date de publication : 1 janvier 2010

Pagination : 100-102

ISSN : 2190-0078

\section{Référence électronique}

Éloïse Adde, "Le Centre d'Études Médiévales de Praque / Centrum medievistických studii (CMS) »,

Revue de l'IFHA [En ligne], 2 | 2010, mis en ligne le 01 février 2013, consulté le 23 avril 2019. URL: http://journals.openedition.org/ifha/235; DOI : 10.4000/ifha.235

Ce document a été généré automatiquement le 23 avril 2019

(CIFHA 


\title{
Le Centre d'Études Médiévales de Prague / Centrum medievistických studií (CMS)
}

\author{
Éloïse Adde
}

1 Le CMS, ou Centre d'Études Médiévales en français, a été créé le 1er juillet 1998 conjointement par la faculté de lettres de l'Université Charles (Prague) et le département de philosophie de l'Académie des sciences de la République tchèque, afin de faire collaborer les chercheurs et spécialistes de ces deux institutions distinctes dans une visée pluridisciplinaire. Le CMS est un lieu de rencontre offrant à son public l'accès à une riche bibliothèque qui sert aussi, avec une capacité d'accueil d'environs quarante personnes, de salle de conférence.

2 Il est dirigé par le professeur Petr Sommer, spécialiste d'archéologie médiévale (christianisation, culture spirituelle au Moyen Âge) qui travaille de concert avec son suppléant František Šmahel, spécialiste de la réforme hussite et de la transition entre le Moyen Âge et la Renaissance, aujourd'hui en fonction à l'Académie des sciences de la République tchèque. Comptant dix-neuf membres permanents, le CMS est une structure importante, incontournable pour aborder l'histoire médiévale des pays tchèques et de l'Europe centrale. Des membres externes jouent un rôle de consultation dans la mise en place du programme scientifique des séminaires. Il s'agit de spécialistes tchèques ou étrangers incontournables dans la recherche médiévale.

3 Le but premier du centre était de soutenir les doctorants travaillant sur des problématiques médiévales (en histoire bien sûr, mais aussi en archéologie, en histoire du droit, en histoire de l'art ou encore en philologie, etc.), de favoriser la synergie et l'émulation, dans le cadre de journées régulières thématiques permettant aux étudiants de présenter leurs travaux, ou bien de l'annuelle «école d'été d'études médiévales » qui se déroule sur plusieurs jours au début du mois de septembre. En proposant des cycles de conférences faisant intervenir des spécialistes de renom originaires des différents pays d'Europe (surtout d'Allemagne) ou d'autres continents, le CMS a élargi sa vocation 
initiale. Il organise ou co-organise aujourd'hui des rencontres scientifiques ainsi que des séminaires et des cycles de conférences de manière très régulière. Citons pour l'année 2009-2010 les colloques suivants: Eigenkirchen, Höfe und Sitze und die Entwicklung von frühmittelalterlichen Eliten in Ostmitteleuropa (mai 2010), Medieval Pilgrim Badges. Prospects of European Research (avril 2010), Universalia - heresis seminaria? Pojmy v bádání o husitství (septembre 2009), Medieval Manuscript Miscellanies: Composition, Authorship, Use.

Le CMS met aussi en œuvre une politique éditoriale importante. Outre les actes des colloques qu'il organise, il édite des recueils d'articles ou autres ouvrages collectifs. Le CMS a également commencé depuis le début des années 2000 la réédition de sources médiévales tchèques (Fontes rerum Bohemicarum, Sbírka pramenů $k$ náboženským dûjinám), ce qui représente un travail d'une importance essentielle dans la mesure où la plupart des éditions de références datent encore du XIXe siècle.

La situation géopolitique de la Bohême médiévale et les thématiques abordées favorisent l'axe République tchèque-Allemagne. De nombreuses publications et journées d'études portent sur des questions propres aux deux espaces géographiques et s'emploient à croiser les regards allemand et tchèque sur des questions aux implications idéologiques pour certaines encore importantes de nos jours (c'est le cas de la colonisation allemande en Bohême au XIIe siècle) ${ }^{1}$ ou bien sur les approches méthodologiques différentes d'un pays à l'autre².

Depuis 2009, le CMS a aussi une revue semestrielle intitulée Studia Mediaevalia Bohemica dont l'avantage est de publier des articles non seulement en tchèque, mais aussi en français et en allemand, et donc de rendre accessibles au public non tchécophone des réflexions importantes sur l'histoire de la Bohême et de l'Europe centrale. N'oublions pas de mentionner le recueil annuel de numismatique : Numismatický sbornik.

7 Le CMS accorde enfin une grande attention à son site qui, en plus de présenter les activités et l'organisation du centre, met en ligne des données importantes. De manière totalement libre, il est possible de consulter les sources médiévales tchèques éditées ( http://147.231.53.91/src/index.php) comme les codex diplomatiques de Bohême, Silésie ou Moravie, les Fontes Rerum Bohemicarum, ou les grandes chroniques tchèques. Dans la liste figurent aussi des usuels importants comme des catalogues de notices de manuscrits: le catalogue de Truhláfi pour la Bibliothèque nationale, le catalogue de Bartoš pour la bibliothèque du Musée national.

Centrum medievistických studií

Akademie vûd âR a Univerzity Karlovy

Jilská 1

11000 Praha 1

tél. : (+420) 222222146

fax : (+420) 222220726 ou (+420) 221183255

Courriel : cms@flu.cas.cz

Internet : http://cms.flu.cas.cz/index.php

Directeur : Petr Sommer 


\section{NOTES}

1. Michael Brauer, Pavlína Rychterová, Martin Wihoda, (dir.), Die mittelalterliche Kolonisation. Vergleichende Untersuchungen, Praha : Filosofia, 2009, 196 p.

2. Pavel Soukup, František Šmahel (dir.), Nãmecká medievistika v ãeských zemích do roku 1945 [La médiévistique allemande dans les pays tchèques jusqu'en 1945], Praha : Filosofia, 2004, 396 p.; František Šmahel, Robert Novotný, Pavel Soukup (dir.), Tschechische Mittelalterforschung 1990-2002, Praha : Filosofia, 2003, 224 p.

\section{AUTEUR}

\section{ÉLOÏSE ADDE}

Éloïse Adde a été boursière d'aide à la mobilité à l'IFHA en 2009-2010. Elle est actuellement chercheuse associée au CEFRES de Prague. 